\title{
Aboveground burial for managing catastrophic losses of livestock
}

\author{
Gary Alan Flory ${ }^{1}$, Robert W. Peer ${ }^{1}$, Robert A. Clark², Mohamed Naceur Baccar ${ }^{3}$, Thanh-Thao Le ${ }^{4}$, Aziz Ben Mbarek
} and Sami Farsi ${ }^{6}$

1. Virginia Department of Environmental Quality, P.O. Box 3000, 4411 Early Road, Harrisonburg, VA 22801, USA; 2. Virginia Cooperative Extension, 600 North Main Street, Suite 100, Woodstock, Virginia 22664-1855; 3. Veterinarian Divisional Inspector, Sub Director of Training and Skills Development, National Center of Zoosanitary Vigilance, Tunis, Tunisia; 4. Department of Health and Environmental Control, Columbia, SC, USA; 5. Veterinarian in Charge of Animal Health, Regional Department for Agricultural Development, Sfax, Tunisia; 6. Veterinarian Divisional Inspector, Head of the Livestock Production District, Regional Department for Agricultural Development, Sfax, Tunisia.

Corresponding author: Gary Alan Flory, e-mail: gary.flory@deq.virginia.gov

Co-authors: RWP: robert.peer@deq.virginia.gov, RAC: raclark@vt.edu, MNB: baccar.vet@gmail.com, TTL: thaotle77@gmail.com, ABM: aziz.veto@hotmail.com, SF: fersisami@yahoo.fr

Received: 17-07-2017, Accepted: 20-08-2017, Published online: 22-09-2017

doi: 10.14202/IJOH.2017.50-56 How to cite this article: Flory GA, Peer RW, Clark RA, Baccar MN, Le TT, Mbarek AB, Farsi S (2017) Aboveground burial for managing catastrophic losses of livestock, Int J One Health 2017;3:50-56.

\begin{abstract}
Background and Aim: Environmental impacts from carcass management are a significant concern globally. Despite a history of costly, ineffective, and environmentally damaging carcass disposal efforts, large animal carcass disposal methods have advanced little in the past decade. An outbreak today will likely be managed with the same carcass disposal techniques used in the previous decades and will likely result in the same economic, health, and environmental impacts. This article overviews the results of one field test that was completed in Virginia (United States) using the aboveground burial (AGB) technique and the disposal of 111 foot-and-mouth disease (FMD) infected sheep in Tunisia using a similar methodology.
\end{abstract}

Materials and Methods: Researchers in the United States conducted a field test to assess the environmental impact and effectiveness of AGB in decomposing livestock carcasses. The system design included a shallow trench excavated into native soil and a carbonaceous base placed on the bottom of the trenches followed by a single layer of animal carcasses. Excavated soils were subsequently placed on top of the animals, and a vegetative layer was established. A similar methodology was used in Tunisia to manage sheep infected with FMDs, Peste des Petits Ruminants virus, and Bluetongue Virus.

Results: The results of the field test in the United States demonstrated a significant carcass degradation during the 1-year period of the project, and the migration of nutrients below the carcasses appears to be limited thereby minimizing the threat of groundwater contamination. The methodology proved practical for the disposal of infected sheep carcasses in Tunisia.

Conclusions: Based on the analysis conducted to date, AGB appears to offer many benefits over traditional burial for catastrophic mortality management. Ongoing research will help to identify limitations of the method and determine where its application during large disease outbreaks or natural disasters is appropriate.

Keywords: aboveground burial, carcass disposal, foot-and-mouth disease, foreign animal diseases, mesophilic static pile composting.

\section{Introduction}

The purpose of this project was to evaluate and operationalize aboveground burial (AGB) as an alternative to existing animal carcass disposal methods. We theorize that AGB will prove to offer many of the benefits of traditional burial but with less environmental impact. Some benefits include low-cost, low-technology, biosecurity, and enhanced environmental protection. These benefits are, especially, important in developing countries where more cost and technology-intensive disposal methods would be impractical.

The direct cost of zoonotic diseases over the past decade has been estimated at more than $\$ 20$ billion

Copyright: Flory, et al. This article is an open access article distributed under the terms of the Creative Commons Attribution 4.0 International License (http://creativecommons.org/licenses/ by/4.0/), which permits unrestricted use, distribution, and reproduction in any medium, provided you give appropriate credit to the original author(s) and the source, provide a link to the Creative Commons license, and indicate if changes were made. The Creative Commons Public Domain Dedication waiver (http:// creativecommons.org/ publicdomain/zero/1.0/) applies to the data made available in this article, unless otherwise stated. with an indirect cost exceeding \$200 billion [1]. This economic impact is not unique to the agricultural sector and affects all individuals, groups, and sectors of the economy. The total economic impact of a foreign animal disease outbreak is generally difficult to calculate as it includes both direct and indirect costs. Direct costs, such as those associated with surveillance, testing, appraisal, depopulation, disposal, cleaning and disinfection, and international trade impacts, are possible to calculate, while indirect costs, including consumer and employment effects, impacts on local and regional economics, future environmental remediation efforts, and changes to import levels can be more difficult to determine. Due to the difficulty in calculating these indirect impacts, the total economic impact of an outbreak will likely be underreported.

Although composting has been successfully implemented during large-scale outbreaks of avian influenza in the United States [2-5], outbreaks of livestock disease represent a greater challenge. Outbreaks of foot-and-mouth disease (FMD) in the 
United Kingdom in 2001 [6] and Taiwan [7], Japan [8], and South Korea [9] in 2010 are clear reminders that carcass disposal is a critical component of an effective disease response strategy. Dramatic photos of cattle burning in open pyres during the 2001 FMD outbreak the United Kingdom resulted in widespread public opposition to open burning. In Japan, the lack of acceptable burial sites resulted in delays in disease eradication efforts and required the Japanese government to implement a vaccinate-to-kill strategy [10]. South Korea's disease eradication efforts resulted in the destruction of $20 \%$ of the country's livestock and the creation of 4700 burial sites [11]. This widespread carcass burial has resulted in concerns about massive environmental impacts associated with this activity. Although investigations to characterize the actual impacts of this activity are in their early phases, many worry that the environmental impacts, including contamination of the drinking water supply, will last for decades.

Failure to create detailed, site-specific carcass disposal plans as part of a comprehensive foreign animal disease response strategy can result in delays in disease eradication efforts. A study of a simulated FMD outbreak in California concluded that delaying the response to a detection from 7 to 22 days increased the mean number of herds under quarantine from 680 to 6200 as well as increased mean economic impact cost from $\$ 2.3$ billion to $\$ 69$ billion [12].

A study published by the United Kingdom Department of Health looked at the potential health impact of various carcass disposal methods [13]. They looked at the specific hazards present during FMD carcass disposal efforts and the associated pathways. Burial was ranked as the highest risk disposal method with rendering posing the least risk. With many different pathways of exposure from burial, including direct contact, recreational water use, water supplies, crops, shellfish, direct contact with contaminated soil, the migration of gasses into buildings, and potential hazards from burial can easily contaminate surrounding farms and drinking water system. These potential hazards include campylobacter, Escherichia coli, Listeria, Salmonella B, anthracis, Cryptosporidium, Giardia, Clostridium tetani, Clostridium botulinum,
Leptospira, Mycobacterium, tuberculosis v. bovis, Yersinia, prions for bovine spongiform encephalopathy (BSE), scrapie, disinfectants, detergents, and hydrogen sulfide. Landfilling infected carcasses were assessed as a lower risk but included similar potential exposure hazards and pathways. Hazards of open burning include particulates, $\mathrm{SO}_{2}, \mathrm{NO}_{2}$, nitrous particles, fuel-specific chemicals, metal salts, polycyclic aromatic hydrocarbons, dioxins, prions for BSE, and scrapie. Open burning pathways of exposure include water supplies, runoff, inhalation, and deposition into the food chain. Chen et al. [14] assessed the emissions of heavy metals from animal carcass incinerators.

With the potential for significant economic and environmental costs associated with ineffective carcass management, foreign animal disease responders need additional disposal methods to support their disease eradication efforts.

\section{Materials and Methods}

\section{Ethical approval}

This article does not contain any studies with live human or animal subjects performed by any of the authors.

\section{Study area}

The demonstration project was conducted in Rockingham County, Virginia, in the eastern part of the United States, and the Tunisian project was located in the western part of Tunisia near the coastal city of Sfax.

\section{Technical approach, Virginia field test}

In April 2015, researchers in Virginia, United States, conducted a field test to assess the environmental impact and effectiveness of AGB in decomposing livestock carcasses [15]. Figure-1 shows a basic diagram of the AGB technique. Four variations of the AGB system were evaluated as summarized in Table-1. The system design included a shallow trench excavated into native soil to a depth of between 18 and 28 inches. Eight inches of loose soil or carbonaceous material were placed on the bottom of the trench (Figure-2), followed by a single layer of animal carcasses (Figure-3). Excavated soils were subsequently placed on top of the animals forming a

Table-1: Summary of treatments used in Virginia field test

\begin{tabular}{|c|c|c|c|c|}
\hline Date of Installation & Design 1 & Design 2 & Design 3 & Design 4 \\
\hline Date of installation & April 17, 2015 & April 17, 2015 & April 17, 2015 & July 9, 2015 \\
\hline Date of seeding & April 29, 2015 & April 29, 2015 & April 29, 2015 & July 23,2015 \\
\hline Trench depth (inch) & 18 & 18 & $\begin{array}{l}\text { NA- Installed at } \\
\text { ground level }\end{array}$ & 28 \\
\hline Carcass underlayment & 8 inch of woodchips & 8 inch of loose soil & 8 inch of woodchips & 8 inch of corn silage \\
\hline Total system height (inch) & 30 & 30 & 36 & 30 \\
\hline Phytoremediation layer & $\begin{array}{l}1 / 2 \text { cool season mix } \\
1 / 2 \text { warm season mix }\end{array}$ & $\begin{array}{l}1 / 2 \text { cool season mix } \\
1 / 2 \text { warm season mix }\end{array}$ & None & $\begin{array}{l}1 / 2 \text { cool season mix } \\
1 / 2 \text { warm season mix }\end{array}$ \\
\hline Animal Carcasses & Two, 1200 lbs. cows & Two, 1200 lbs. cows & Two, 1200 lbs. cows & Two, 1200 lbs. cows \\
\hline System cap & $\begin{array}{l}\text { Soil from the } \\
\text { excavation }\end{array}$ & $\begin{array}{l}\text { Soil from the } \\
\text { excavation }\end{array}$ & $\begin{array}{l}\text { Mix of } 10 \% \text { clay, } \\
10 \% \text { poultry litter }\end{array}$ & $\begin{array}{l}8 \text { inch of corn silage } \\
\text { covered }\end{array}$ \\
\hline
\end{tabular}




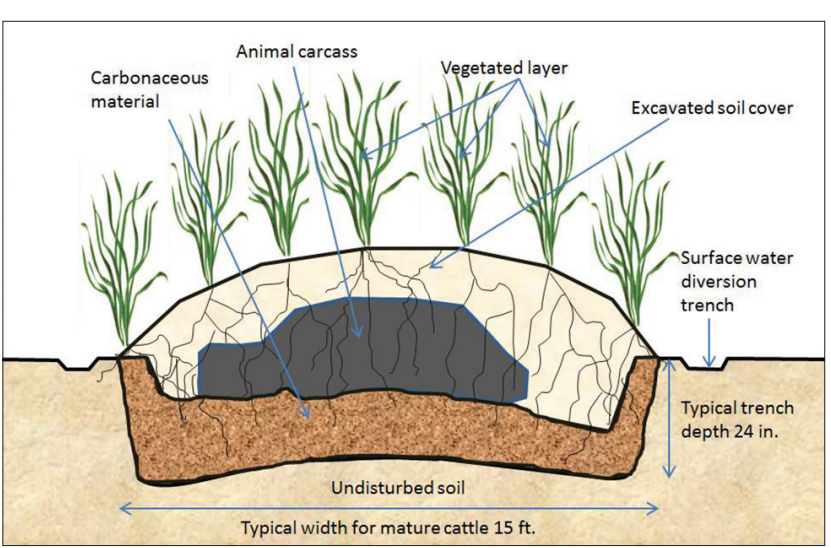

Figure-1: Cross section of aboveground burial system.

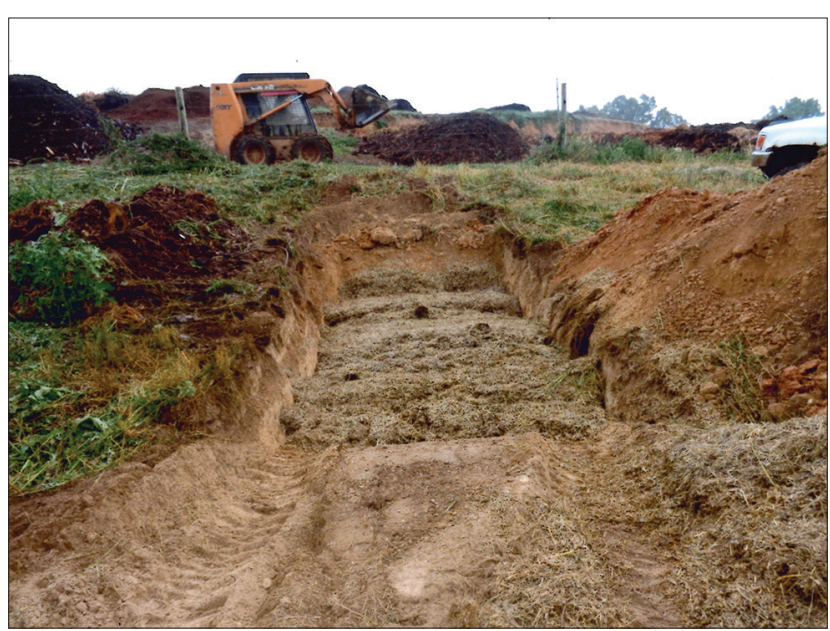

Figure-2: AGB trench ready for carcasses.

mound on which the vegetative layer was established (Figure-4). Finally, a perimeter trench was placed around the mound to prevent the intrusion of surface water into the system. The site was visited weekly for the $1^{\text {st }}$ month following installation and then once per month thereafter for the next year. Visual observations and pictures were taken to document the results. 1 year after the ABG field test was initiated, investigators excavated to the bottom of each design to assess the extent of carcass degradation and to collect soil borings for subsequent analysis. The assessment was simply a visual observation of degradation. In addition, soil samples were collected using a soil auger at depths shown in Figure-5. Each sample consisted of a single core from each of the four treatments and two samples from adjacent areas where animals were not buried. Soil samples were analyzed for total N, ammonium $\mathrm{N}$, nitrate $\mathrm{N}$, mehlich $\mathrm{P}$, and $\mathrm{Ph}$.

\section{Technical approach, Tunisia}

After the seizure of 151 sheep from the illegal trade by the Tunisian customs authorities, the animals were placed in a quarantine center. For the duration of a week, clinical signs were observed, and tissue and blood samples were taken to be analyzed for infectious diseases. The results of these tests showed that serological traces of the FMD virus using the $3 \mathrm{ABC}$

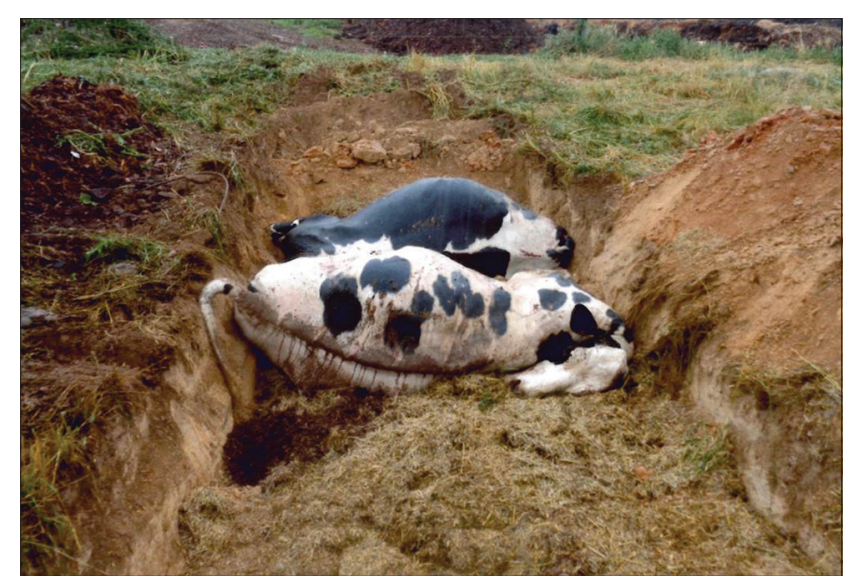

Figure-3: AGB trench with bovine carcasses.

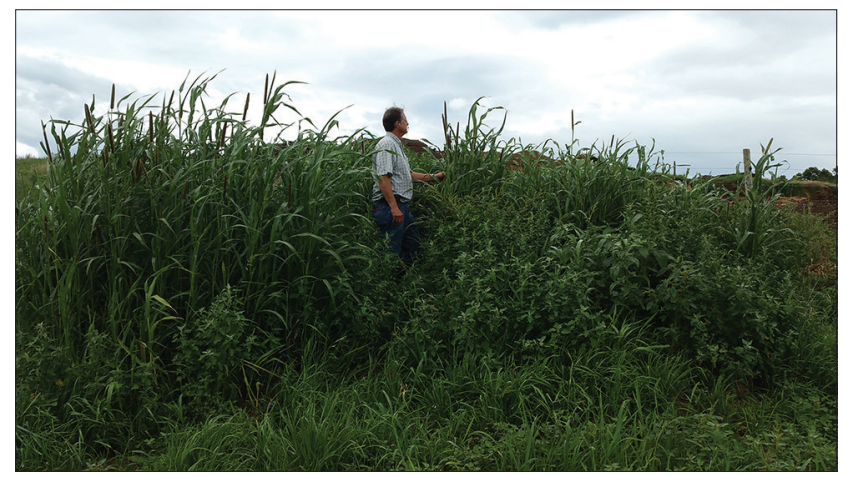

Figure-4: Vegetated AGB system.

test with Peste des Petits Ruminants Virus (PPRV) and Bluetongue Virus found using polymerase chain reaction analysis. Based on these results, the decision was made to depopulate and dispose of the herd.

The team chose the AGB method for the disposal of 111 of the 151 animals because it appeared to be an easy method for implementation with a low cost of execution. 40 sheep died from PPRV and were managed through traditional burial. In addition, they wanted to use this method to test and validate the effectiveness of this method as demonstrated in Virginia [15].

Initially, the animals were to be slaughtered and buried on the site of the quarantine center. However, adjacent residents did not want these animals buried at the quarantine center due to potential odors and the risk of pathogen spread to their livestock. For this reason, the team relocated the disposal site to a more remote location with clay soils.

The team excavated a trench 27 inches wide by 60 inches deep and 230 feet long (Figure-6) and added about 12 inches layer of straw at the bottom of the trench. Next, they placed 111 sheep carcasses (total weight of approximately 9400 pounds) side-by-side in a longitudinal position (Figure-7) and then covered them with 60 inches of excavated soil (Figure-8). Finally, they seeded alfalfa on the mound. Based on the size of the trench and the number of animals, the AGB method resulted in a carcass density of $4.66 \mathrm{f}^{2}$ per carcass. 


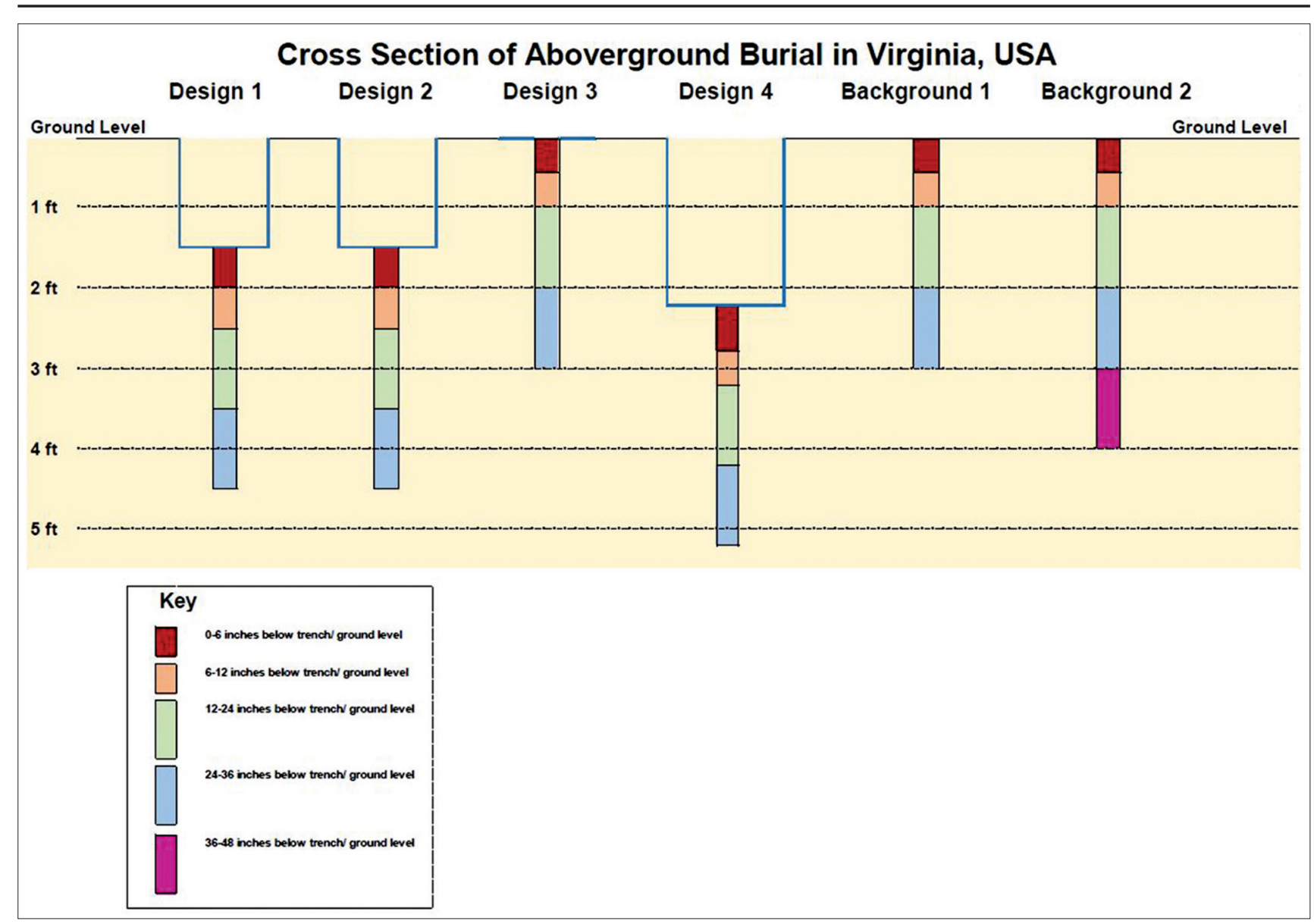

Figure-5: Cross section of AGB project area.

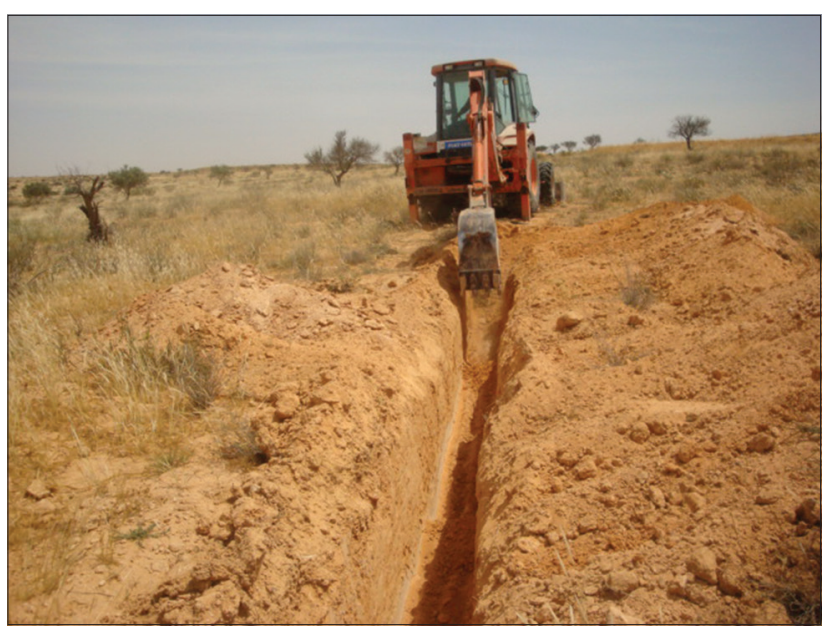

Figure-6: Preparation of AGB trench.

\section{Results and Discussion}

\section{Virginia field test}

Two weeks after installation of the AGB system, the following observations were made:

- There was a significant crack in Design 3 within the $1^{\text {st }}$ week of burial. This crack attracted flies. Larvae were observed approximately 2 weeks after the animals were buried

- Small cracks had formed on the surfaces of Designs 1 and 2 approximately 2 weeks following placement of the carcasses. However,

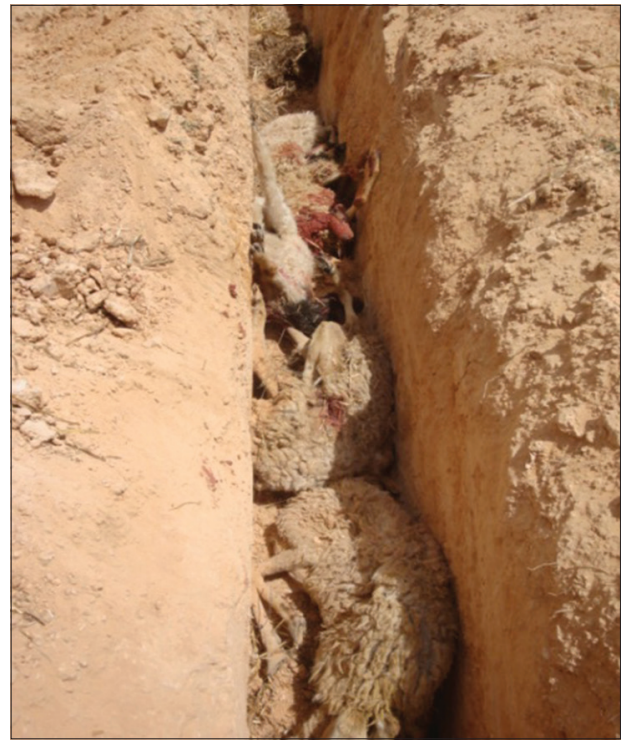

Figure-7: Sheep carcasses placed in AGB trench.

minimal odor was detected from these cracks, and only, a few flies and no fly larvae were observed

- The authors believe that all of the cracks in Designs 1, 2, and 3 could have easily been rectified with a little additional soil

- Total height on all designs had decreased 6-8 inches by week 4 


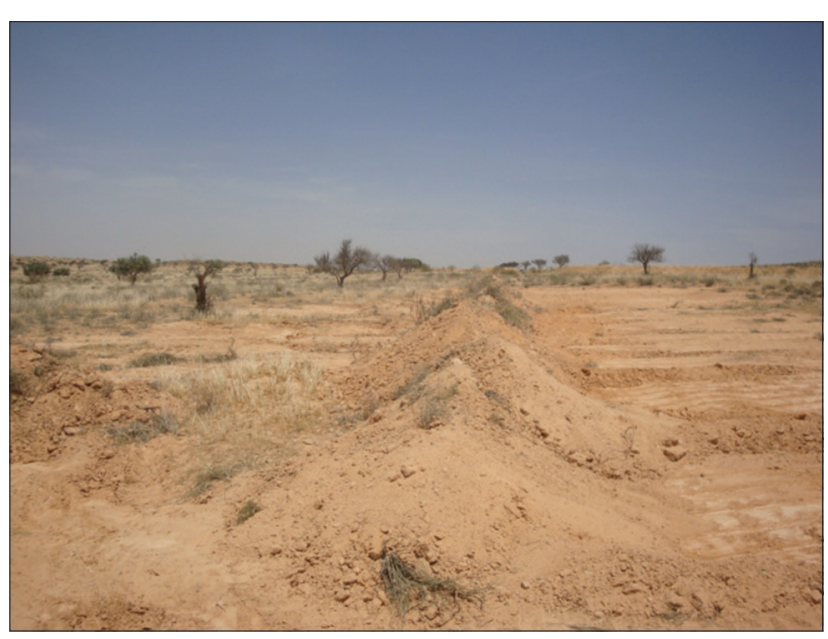

Figure-8: Completed AGB system.

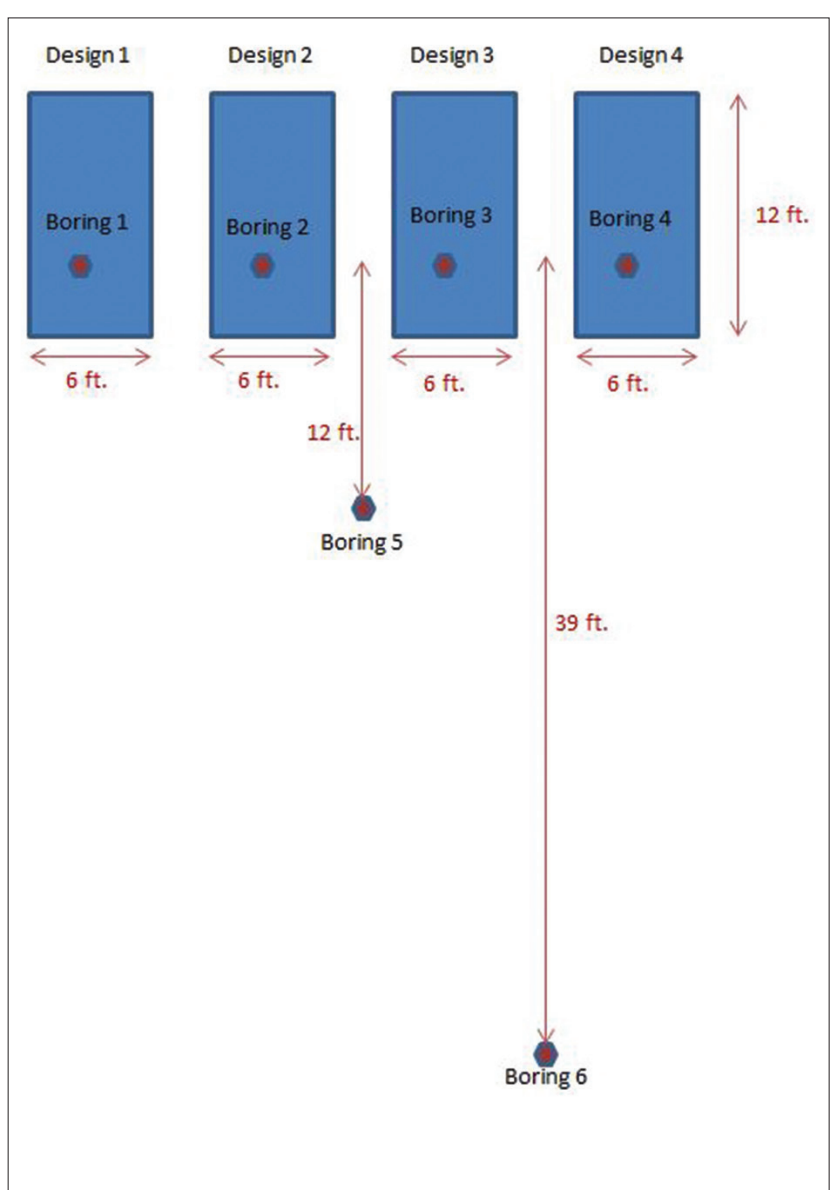

Figure-9: Plan view of AGB project area.

- Cool-season grasses were well established, but warm-season grasses had not germinated. The animals were placed in April. We speculate that the weather was too cool for the warm season blend to germinate and become established

- No leachate or free liquids were observed at the surface from any of the designs.

One year following installation of each of the AGB variations, investigators excavated to the bottom of each design to assess the extent of carcass degradation and to conduct borings for subsequent soil analysis. In Designs 1 through 3, carcass degradation was

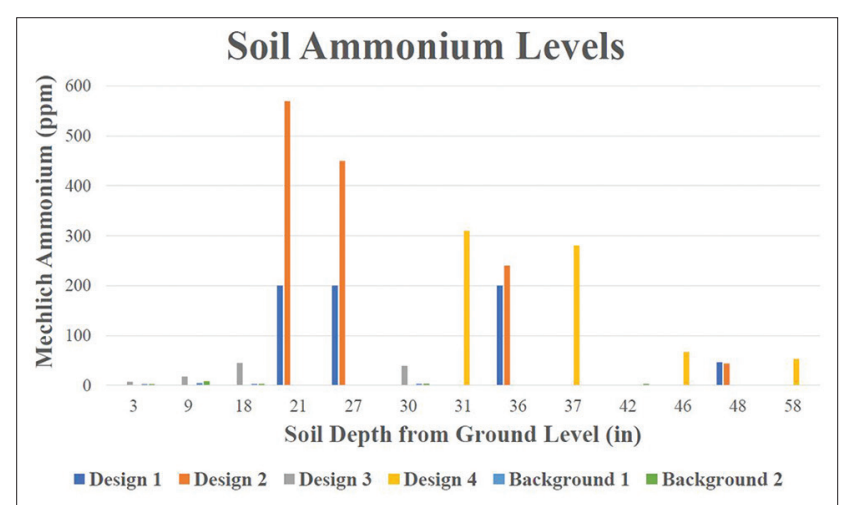

Figure-10: Soil ammonium levels.

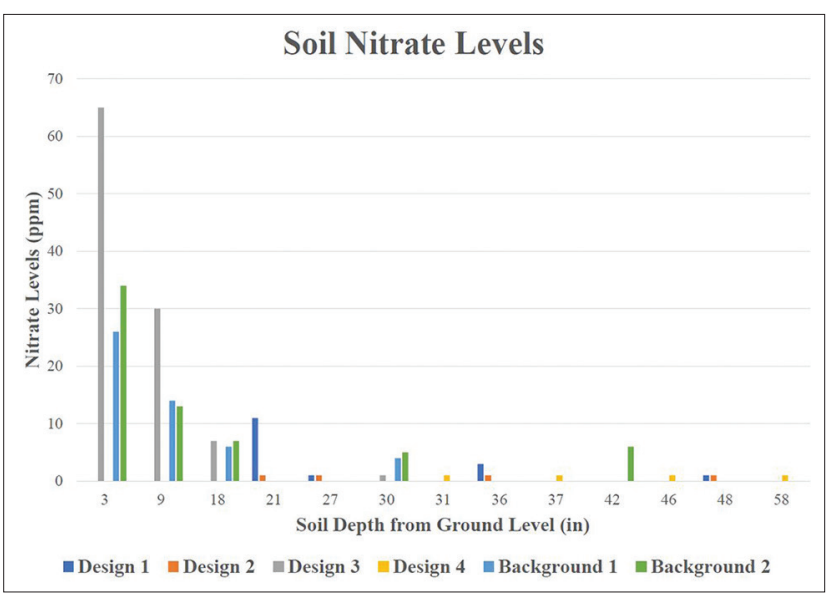

Figure-11: Soil nitrate levels.

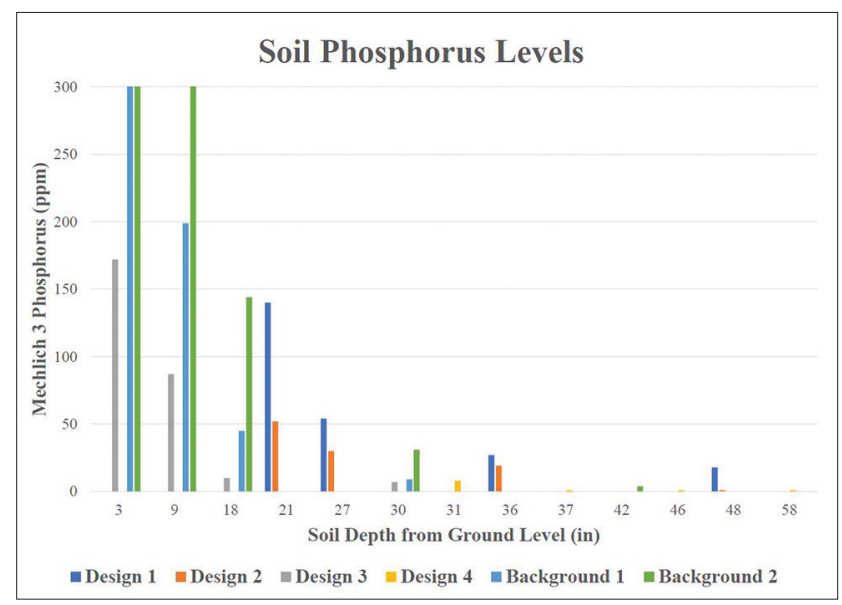

Figure-12: Soil phosphorus levels.

approximately $95 \%$ with only the larger bones remaining. Carcass degradation in Design 4 was only around $60 \%$ with some flesh, hide, and fatty tissue remaining. The depth of Designs 1 through 3 was 18 inches or shallower, while Design 4 was 28 inches deep. We presume that the deeper design contributed to an anaerobic environment in the trench which inhibited the biological activity found in the shallower designs (no actual oxygen readings were taken).

It is important to note that there were no replications to any of the treatments and the soil sample consisted of a single core of soil collected beneath 


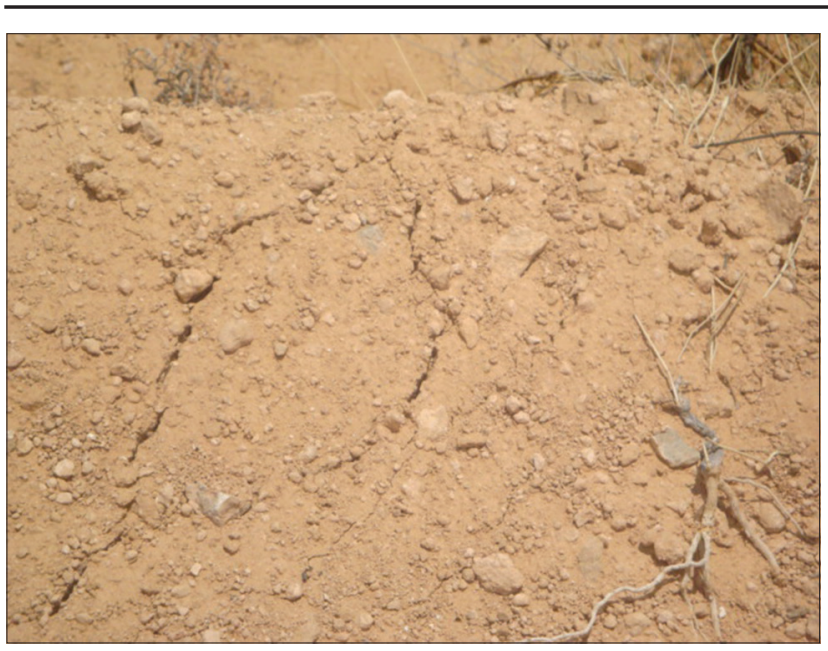

Figure-13: Cracks observed at 4 weeks.

the bottom of each treatment. Soil borings were collected as shown in Figure-9. Nitrogen concentrations appeared to be elevated higher than background levels for Designs 1, 2, and 4. This nitrogen was in the form of ammonium (Figure-10), and we presume organic nitrogen (it was not nitrate because nitrate concentrations were low as shown in Figure-11). We presume that there was not enough oxygen present for nitrification. Nitrogen components, which are typically mobile, were not present in elevated concentrations at depths of $>24$ " below the bottom of each trench. In regard to phosphorus, we anticipated that we would see an elevated soil test phosphorus concentration immediately beneath the animal carcass. Thus, the sampling depth was adjusted to 0-6" and 6-12" immediately beneath each design. The results shown in Figure-12 are not clear as to the fate of the phosphorus. Potential explanations are either (1) the elevated soil test phosphorus in the surface soils combined with historical plowing could have elevated subsoil phosphorus levels or (2) the phosphorus from the mortality was contained in the material excavated before sampling or (3) the mehlich 3 extraction procedure did not capture the phosphorus. Phosphorus does not typically leach through soils with a high clay content. Moreover, thus, we do not anticipate a problem with phosphorus leaching. We plan to continue to document phosphorus movement in the future field tests.

\section{Tunisia project}

The AGB mound was completed on May 05, 2017. The following observations were made 1 week later:

- Absence of liquid from the ditch

- Absence of odors

- Absence of cracks

- Absence of flies.

On June 2, 2017, 4 weeks after AGB pit completion, only a few cracks were observed (Figure-13). Due to a lack of precipitation, the alfalfa had not yet germinated.

Following the use of this technical approach and considering the first observed results, we have demonstrated that $\mathrm{ABG}$ may be an effective technique and which is easy to set up. However, further work will need to be completed to assess carcass decomposition and virus inactivation. Furthermore, we made an estimate of the overall cost of the Tunisia operation, and the cost did not exceed $\$ 300$ US.

To evaluate the effectiveness of this method, we have designed a monitoring schedule that will include sampling to test the viability of the viruses under these conditions and to evaluate the state of decomposition of the carcasses.

\section{Practicality of the method}

It is our initial observations based on these two field tests that AGB may offer many of the benefits of traditional on-site burial while minimizing the potential for environmental impact. Some potential benefits include:

- Simple, low-technology, design allows implementation with minimal training

- Low execution cost

- Reduces the risk of groundwater contamination be increasing the separation from the groundwater table

- Relatively rapid to install

- Absorption of decomposition fluids by the layer of carbonaceous material to minimize negative environmental impacts

- Reduces the potential for disease spread by keeping the material on the farm and minimizing external inputs

- Flexibility to implement as a temporary or permanent solution

- Carcasses could be excavated for permanent disposal (incineration, landfilling, and composting) after initial disease eradication efforts

- AGB mounds could be regraded and revegetated after complete carcass decomposition.

- $\mathrm{AGB}$ has the potential of being implemented to manage carcasses during a natural disaster or foreign animal disease outbreak. Additional research, however, will be needed to ascertain if specific diseases are destroyed during the AGB process.

Based on our visual observation, we believe that AGB and thermophilic composting are similar in that both methods rely on aerobic biological activity to decompose the animal carcasses. With AGB, we are attempting to place the carcasses in the biologically active soil zone where biological activity is enhanced by the addition of a carbonaceous layer similar to composting.

However, unlike thermophilic composting, we do not believe that AGB promotes the activity of thermophilic bacteria and does not generate the high temperatures that you would expect during windrow composting. As a result, pathogen inactivation will not occur from heat. We will need to engage experts in pathogen viability to document pathogen destruction. It is our 
hope that the combination of predation by microbial populations, a shift in $\mathrm{pH}$, and the absence of a living host will inactivate enough pathogen to make this a viable option for animal disease management.

While thermophilic composting may be advantageous in many circumstances, during the response to an extremely contagious disease such as FMD, AGB can be implemented more quickly to contain the infected carcasses and reduce the potential for the spread of disease.

Before recommending this method for full-scale implementation during a catastrophic livestock mortality event, additional research and field testing will be necessary. Our research team is currently preparing to initiate further research to:

- Evaluate and demonstrate the use of AGB on two sites using two different treatments and compare the effectiveness of the two treatments with the effectiveness of traditional burial

- Evaluate the effect of each treatment on nutrient transport below the burial site

- Assess the cost of AGB versus traditional burial

- Conduct outreach and education in Virginia about AGB.

Furthermore, additional research will be needed to determine if AGB will reduce the spread of disease and/or if this technique reduces the viability of specific pathogens through mechanisms such as a shift in $\mathrm{pH}$ and predation by natural bacterial populations.

\section{Conclusions}

Based on the analysis conducted to date, AGB appears to offer many benefits over traditional burial for catastrophic mortality management. Application of this method to manage sheep infected with FMD, bluetongue, and sheep plague in Tunisia demonstrated its practicality in that environment. Site design will be critical to the success of this option. Soil characteristics and depth to groundwater are the key parameters to consider to ensure minimal environmental impact. Ongoing research will help to identify the limitations of the method and determine where its application during large disease outbreaks or natural disasters is appropriate.

\section{Authors' Contributions}

GAF: Study conduction, data collection, analyses, reference search, and manuscript writing. RWP: Study conduction, data collection, analyses, and manuscript writing. RAC: Study conduction, data collection, analyses, and manuscript reviewing. MNB: Study conduction, data collection, analyses, and manuscript writing. TTL: Analysis, graphic representation of results, and manuscript review. ABM: Study conduction, data collection, and manuscript review. SF: Study conduction, data collection, and manuscript review. All authors read and approved the final manuscript.

\section{Acknowledgments}

The authors recognize Kenneth Knicely for providing the site and input in the design of the Virginia Field Test and Waypoint Analytical Laboratory for their assistance with the soil analysis. Both projects were conducted without additional outside funding.

\section{Competing Interests}

The authors declare that they have no competing interests.

\section{References}

1. World Bank. People, Pathogens and Our Plant. Towards a Once Health Approach for Controlling. Vol. 1. Zoonotic Diseases Report, 50833-GLB; 2010.

2. Miller LP, Flory GA, Bonhotal J. HPAI Outbreak 20142015: Mortality Composting Protocol for Avian Influenza Infected Flocks. United States Department of Agriculture Guidance, 24 September; 2015

3. Flory GA. U.S. Response to outbreaks of avian influenza. Domest Prep J 2016;12:38-41.

4. Bendfeldt ES, Peer RW, Flory GA. Lessons learned from avian influenza outbreaks in Virginia 1984-2005. In: Proceedings of the Symposium on Composting Mortalities and Slaughterhouse Residuals. Portland, Maine, 24-25, May; 2005.

5. Flory GA, Peer RW. Composting solution to avian flu mortality management. Biocycle 2016;57:37-40.

6. Environment Agency. The environmental impact of the foot and mouth disease outbreak: An interim assessment. In: Environment Agency-434 Foot and Mouth Task Force. Bristol, United Kingdom: Environment Agency; 2002.

7. Hseu ZY, Chen ZS. Experiences of mass pig carcass disposal related to groundwater quality monitoring in Taiwan. Sustainability 2016;9:46.

8. Hayama Y, Muroga N, Nishida T, Kobayashi S, Tsutsui T. Risk factors for local spread of foot-and-mouth disease, 2010 epidemic in Japan. Res Vet Sci 2012;93:631-5.

9. Kim HS, Kim K. Microbial and chemical contamination of groundwater around livestock mortality burial sites in Korea-a 456 review. Geosci J 2012;16:479-89.

10. Muroga N, Hayama Y, Yamamoto T, Kurogi A, Tsuda T, Tsutsui T. The 2010 foot-and-mouth disease epidemic in Japan. J Vet Med Sci 2012;74:399-404.

11. Kim MH, Ko CR, Kim G. Cost of analysis of carcass burial site construction: Focused on the foot and mouth disease 2011, South Korea. Environ Eng Res 2015;20:356-62.

12. Carpenter TA, O'brien JM, Hagerman AD, McCarl BA. Epidemic and economic impacts of a delayed detection of foot-and mouth disease: A case study of a simulated outbreak in California. J Vet Diagn Invest 2011;23:26-33.

13. Department of Health. A Rapid Qualitative Assessment of Possible Risks to Public Health from Current Foot and Mouth Disposal Options. Main Report, June. London: Department of Health; 2001.

14. Chen SJ, Hung MC, Huang KL, Hwang WI. Emission of heavy metals from animal carcass incinerators in Taiwan. Chemosphere 2004;55:1197-205.

15. Flory GA, Peer RW. Mesophillic static pile composting of animal carcasses. Biocycle 2017;58:65-8. 